\title{
Ageing of UHMWPE in presence of simulated synovial fluid
}

\author{
Annamaria Visco ${ }^{\mathrm{a}, \mathrm{b}, *}$, Emmanuel Richaud ${ }^{\mathrm{c}}$, Cristina Scolaro ${ }^{\mathrm{a}}$ \\ a Department of Engineering, University of Messina, C.da Di Dio, 98166 Messina, Italy \\ ${ }^{\mathrm{b}}$ Institute for Polymers, Composites and Biomaterials - CNR IPCB, Via Paolo Gaifami 18, 9-95126 Catania, Italy \\ ${ }^{\mathrm{C}}$ Laboratoire PIMM, Arts et Metiers Institute of Technology, CNRS, Cnam, HESAM University, 151 boulevard de l'Hopital, 75013 Paris France
}

Keywords:

UHMWPE

Simulated synovial fluid

Diffusion

Thermal ageing

Kinetic model

\begin{abstract}
A B S T R A C T
In this paper, the biomedical grade Ultra High Molecular Weight Polyethylene (UHMWPE) has been soaked at different temperatures in Simulated Synovial Fluid (SSF); diffusion coefficient, hardness, roughness and wettability has been evaluated. Then, the $37^{\circ} \mathrm{C}$ (body temperature) soaked-polyethylene sample was aged at $80^{\circ} \mathrm{C}$ and monitored by InfraRed spectroscopy (oxidation trackers) and GPC (for molar mass changes) to observe the long-term degrading action of SSF. Finally, a kinetic model has been performed to simulate the ageing. Results highlighted as SFF smooths the material's surface, diffusing within the polymer helped by the temperature growth. The oxidation kinetic study stated that PE is more degraded by SSF with a significant decrease of molecular weight of a factor 2 if helped by the ageing temperature of $80^{\circ} \mathrm{C}$. Simulation models are effective to theoretically reproduce pro-degradation mechanisms induced by SSF on UHMWPE at $80^{\circ} \mathrm{C}$.
\end{abstract}

\section{Introduction}

Ultra High Molecular Weight-Polyethylene (UHMWPE) is usually used in high wear/abrasion resistance applications, such as in snowboards, pipes for dredging, vehicle armor, cut-resistant gloves, bow strings, climbing equipment, fishing line, spear lines, high performance sails, suspension lines on sport parachutes, etc.[1].

In addition, since 1961 to date UHMWPE has been considered the standard material For Joint Replacement (JR) in artificial knees and hips prosthesis for its high strength, chemical resistance, and bio-compatibility $[2,3]$.

Identically to polymer - metal debonding at the interface in the case of bonded joints [4,5], adhesive debonding can be an issue induced either by the plasticization of the glue or SSF diffusion through the PE can also favor the debonding. After implantation in the human body, UHMWPE can also undergo bio-degradation (due to the physiological environment), mechanical degradation (for the sliding friction against the other metallic or ceramic harder components of the artificial mobile prostheses) [6-8]. Thus, the UHMWPE represents the weakest part of the artificial joint. During its use, plastic debris are the consequence of the degradation mechanisms; debris give rise to adverse reactions which lead to osteolysis and

* Corresponding author at: Department of Engineering, University of Messina, C.da Di Dio, 98166 Messina, Italy.

E-mail addresses: annamaria.visco@unime.it (A. Visco), emmanuel.richaud@ensam.eu (E. Richaud), cristina.scolaro@unime.it (C. Scolaro). aseptic loosening of the prosthesis causing the failure of the entire joint and, hence, the revision surgery.

Wear mechanism is accelerated by the chemical reactions which take place during the in vivo contact with the biological fluids [9]. UHMWPE undergoes ageing in which oxygen is the main cause of material's degradation. Thus, the contact of polyethylene in synovial fluid may causes an oxidative degradation of UHMWPE $[10,11]$ with a progressive mechanical property falling, both in tensile as in wear resistance [12].

Degradation of UHMWPE bearings during implantation is well known and studied for several decades: Eyerer and Ke [13] highlighted property changes in UHMWPE hip joint cups with an evident density increase with implantation time, in dependence from the loading conditions. Jahan et al. [14] observed as the temperature rise forms high-wear areas and the high-free-radical regions in acetabular cups during the in vitro frictional wear stress test. This is due to a combined chemical and mechanical degradation effect.

Recently, literature studies addressed on research topics concerning the study of the degrading action of synovial and its effect on the mechanical and wear resistance of UHMWPE in vitro. For example, Costa el al. [15] analyzed some hip prosthesis retrieved after surgical revision of patients due to the aseptic failure. They found that apolar components of synovial liquid diffuse into UHMWPE during implant life decreasing the mechanical properties of UHMWPE. In particular, the ultimate tensile strength and ultimate elongation decrease depending on both the amount and 
chemical nature of the diffusant. Chandrasekaran et al. [16] studied the tribological behavior of UHMWPE in dry and wet condition (lubricated with bovine-globulin/bovine-albumin proteins). Their results highlighted as complex wear mechanisms occurs in UHMWPE (adhesion, fatigue, corrosive and abrasive wear) and that UHMWPE undergoes to a plastic macromolecular chains distortion (thus degrading faster) if sliding occurs in presence of proteins (such as albumin, $\alpha$-globulin, $\gamma$-globulin). James et al. [17] and Costa et al. [13] demonstrated that the implanted PE component uptake a certain amount of lipids in the human body. Subsequently, Oral et al. [18] and Sakoda et al. [19] suggested that the diffused lipid molecules accelerated the oxidative degradation of UHMWPE. Other factors, such as heat, cyclic vibration, shearing action, could improve even more the degrading reaction.

Human joints usually work immersed in Synovial Fluid (SF), the natural lubricating film mainly composed of lipids, proteins, polysaccharides, and hyaluronic acid (HA). HA has good tribological properties thanks to its high viscosity [20]. However, SF is not available because it cannot be extracted from the human body except in minimal doses.

Calf or Bovine Serum (BS) is rather used for in vitro experimentation because it has properties very similar to human ones according to the American Standard Testing Materials (ASTM) [21]. In the scientific panorama there is no full agreement regarding the use of BS for tribological tests because the concentration of proteins can be very different with a consequent different effect on the mechanical behavior of the artificial prosthetic joints [22]. Alternatively, researchers can also use the Simulated Body Fluid (SBF) or the Simulated Synovial Fluid (SSF) consisting mainly of HA without proteins $[23,24]$. Once absorbed by the biomedical polyethylene, HA improves the lubrication of UHMWPE. Several Authors studied the bulk changes induced in the polymeric structure by biodegradation.

S.Ge et al. found that wear volume increases up to 6 times for one-year degraded UHMWPE in Simulated Body Fluid (SBF) [6]. They checked the crystalline degree decreasing and hypotized as biodegradation results from oxidative degradation, hydrolysis, biodeterioration, and tribo-fatigue. Cornwall et al. [25] studied the micro-structural changes of UHMWPE after a wear mechanism in vivo. Authors highlighted as the post processing microstructure of UHMWPE may influence its surface degradation mechanism and the overall wear performance. Thus, biodegradation highly influences wear performance of UHMWPE determining the artificial joint reliability.

In our previous papers we studied the wear performance of UHMWPE in simulated synovial fluid (SSF) [24,26]. In this paper we:

a) studied the diffusion of SSF inside UHMWPE with the consequent surface changes (by means of surface roughness, Shore-D Hardness, SSF wettability evaluation).

b) studied the oxidation kinetics of SSF on UHMWPE, before and after the aging at $80^{\circ} \mathrm{C}$, by means of FTIR and GPC technique for investigating long-term molecular and macromolecular changes.

c) proposed a first kinetic modelling to describe the accelerating of SSF on PE thermal oxidation to help the more general prediction of all the UHMWPE based materials degradation behavior.

At the best of our knowledge, these aspects have not already investigated so far.

\section{Materials and methods}

Medical grade GUR1020-UHMWPE powder (average molecular weight of $2-4 \times 10^{6} \mathrm{~g} / \mathrm{mol}, \mathrm{d}=0.93 \mathrm{~g} / \mathrm{cm}^{3}$ without calcium stearate, supplied by Celanese, code "PE") was molded in films. No stabilizing additives have been added to UHMWPE (i.e. Vitamin E, etc.).Rectangular shape has been used for GPC and FTIR tests ("type A" sample, $4 \mathrm{~cm}$ x $1 \mathrm{~cm}$ x $0.16 \mathrm{~mm}$ thick, Figure 1 (a)). Square shape has been used for absorption test according to ASTM D570 standard $(60 \mathrm{~mm} \times 60 \mathrm{~mm}, 1 \mathrm{~mm}$ thick, or "type B" sample) (Figure 1 (b)).

Sheets were prepared by compression molding $\left(\mathrm{T}=200^{\circ} \mathrm{C}\right.$, Time $=20$ minutes, Pressure $=20 \mathrm{MPa})$ and Teflon ${ }^{\circledR}$ sheets $(0.1$ $\mathrm{mm}$ thick) for sample releasing.

Both A and B samples have been soaked in Simulated Synovial Fluid (SSF) which contains 0.3 wt \% HA in phosphate buffered saline solution ( $\mathrm{pH} 7.4)$. Inorganic electrolyte concentration was: $153.1 \mathrm{mM}$ of $\mathrm{Na}^{+}, 4.2 \mathrm{mM}$ of $\mathrm{K}^{+}, 139.6 \mathrm{mM}$ of $\mathrm{Cl}^{-}$, and $9.6 \mathrm{mM}$ of phosphate buffer.

Diffusion tests have been carried out according to ASTM D570 standard on type B sample soaked in $100 \mathrm{ml}$ of SSF at $\mathrm{T}=20^{\circ} \mathrm{C}$, $37^{\circ} \mathrm{C}$ and $100^{\circ} \mathrm{C}$, in a bath of paraffin oil to ensure the constant temperature, magnetic stirring $=200 \mathrm{rpm}$ (rate per minute), and relative humidity $\mathrm{RH}=54 \%$ (Figure 1 (c)). Although the boiling temperature of SSF is of about $146^{\circ} \mathrm{C}$, it evaporates under stirring at much lower temperatures. Thus, adsorption test at temperature higher than $100^{\circ} \mathrm{C}$ had no scientific relevance. Furthermore, since the melting temperature of UHMWPE is of about $135^{\circ} \mathrm{C}$, at the temperature of higher than $100^{\circ} \mathrm{C}$ it starts to soften. Before each test, samples were dried in an oven for $24 \mathrm{~h}$ at $50^{\circ} \mathrm{C}$ (ASTM D570) and then placed in a desiccator until it was cooled. Afterward, samples were weighed by a OHAUS Explorer Pro balance with sensibility of $0.1 \mathrm{mg}$ in the temporal range $0 \div 420 \mathrm{~min}$. A constant water level was always maintained by adding SSF. Samples were removed from bath periodically within the range 1 hour-400 hours, dried with a lint free cloth, and weighed. Water absorption percentage was expressed as:

Water Absorption $=\left(\frac{\boldsymbol{P}_{\boldsymbol{W}}-\mathrm{P}_{\boldsymbol{D}}}{\boldsymbol{P}_{\boldsymbol{D}}}\right) \boldsymbol{x} 100$

where $P w$ is the wet weight, $P_{D}$ is the dry weight of the sample. Water diffusion coefficient or diffusivity $(D)$ was calculated by the equation [27]:

$\boldsymbol{D}=\pi\left(\frac{\boldsymbol{h}}{4 \boldsymbol{M}_{\infty}}\right)^{2}\left(\frac{\boldsymbol{M}_{\infty}-\boldsymbol{M}_{1}}{\sqrt{\boldsymbol{t}_{\infty}}-\sqrt{\boldsymbol{t}_{1}}}\right)^{2}\left(1+\frac{\boldsymbol{h}}{\boldsymbol{L}}+\frac{\boldsymbol{h}}{\boldsymbol{w}}\right)^{-2}$

where $h, L$ and $w$ are thickness, length and width of the sample, $M_{1}$ and $M_{\infty}$ are moisture contests at time $t_{1}$ and $t_{\infty}$, respectively. $t_{1}$ is the initial time ( 0 hours) and $t_{\infty}$ is the time at which the moisture content became constant or maximum $\left(M_{\infty}\right)$.

The mean differences and standard deviations of diffusivity $(D)$ the three different temperatures $\left(20^{\circ} \mathrm{C}, 37^{\circ} \mathrm{C}\right.$ and $\left.100^{\circ} \mathrm{C}\right)$ were calculated.

Diffusion data verification analysis has been performed by D'Agostino \& Pearson test for the normality of the distribution and the Levene test for the homogeneity of variances.

Data were normally distributed and homogenous; therefore, they were statistically analyzed by using one-way analysis of variance (ANOVA) and Bonferroni post hoc test for multiple comparisons at a level of significance set at $\mathrm{P}<0.05$ (Prism 8.4.1; GraphPad Software, Inc, La Jolla, CA).

The wet ability of SSF on both samples was evaluated by measuring ten times the height $h(\mathrm{~mm})$ and the base diameter $d(\mathrm{~mm})$ of the $1 \mu L$ drops at room temperature and pressure, relative humidity $\mathrm{RH}$ of $35 \%$. Contact angle $\theta$ have been evaluated by the sessile drops method (ASTM D7334) [28,29]:

$\theta_{w}=2 \operatorname{arctg}\left(\frac{2 \boldsymbol{h}}{\boldsymbol{d}}\right)$ 

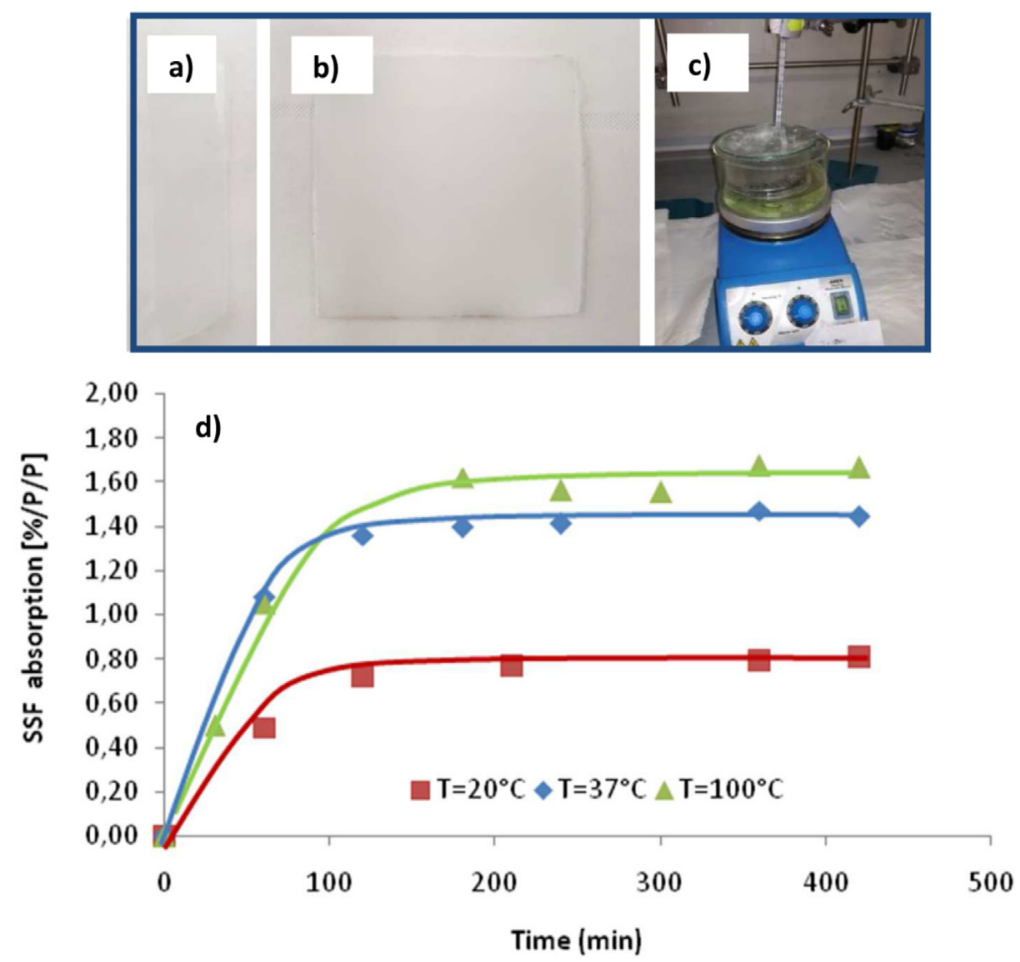

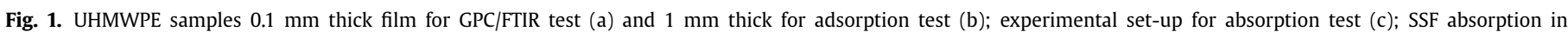
UHMWPE samples at different temperatures, ASTM D570 (d).

$\theta_{Y}=\arccos \left(\frac{\cos \theta_{w}}{\boldsymbol{r}}\right)$

Where $d$ and $h$ are the diameter and height (both in $\mathrm{mm}$ ), respectively of the drop, $\theta_{w}$ is the Wenzel angle of effective contact of a rough surface real, $r$ is the surface roughness, and $\theta_{Y}$ is the Young contact angle of equilibrium on perfectly smooth surface.

The surface roughness $(R z)$ was calculated by a Bruker Dektak XT profilometer:

$\boldsymbol{R}_{z}=\frac{1}{5}\left(\sum_{i=1}^{n} y_{p i}+\sum_{i=1}^{n} y_{v i}\right)$

Where $y_{p i}$ are the ordinates of the $\mathrm{n}$ number five highest peaks $(\mathrm{n}=5)$ and $y_{v \mathrm{i}}$ are the ordinates of the five deepest valleys $(\mathrm{n}=5)$ in reference to the middle line. The system has a vertical resolution of $0.1 \mathrm{~nm}$, a vertical range of $1 \mathrm{~mm}$ and a scan surface speed of 1 $\mathrm{mm} \mathrm{s}^{-1}$.

SHORE D Hardness mechanical tests measurements were performed by means of a PCE-HT 210, according to the ASTM D 2240 international protocol.

GPC analyses were performed using an Agilent HT 220 system equipped with a refractive index (RI) detector in 1,2,4trichlorobenzene (TCB) stabilized with $0.0125 \%$ BHT at $135^{\circ} \mathrm{C}$ as mobile phase with two PLgelOlexis columns (Agilent Technology) as stationary phase. PE films were dissolved in about $3 \mathrm{~g} \mathrm{~L}^{-1}$ of 1,2,4-Trichlorobenzene (TCB). The elution method consisted in an isocratic step at $1 \mathrm{~mL} \mathrm{~min}{ }^{-1}$ flow of TCB for $30 \mathrm{~min}$ at $135^{\circ} \mathrm{C}$. The calibration was done with polystyrene (PS) standards. Molar masses were then estimated using the universal calibration with $\mathrm{K}=12.1 \times 10^{5} \mathrm{dg} \mathrm{L}^{-1}$ and $\alpha=0.707$ for PS, and $\mathrm{K}=40.6 \times 10^{5}$ and $\alpha=0.725$ for PE [30].

FTIR in transmission mode were performed on free standing 100 $\mu \mathrm{m}$ films using a Frontier 100 apparatus (PerkinElmer) by averaging 16 scans with a $4 \mathrm{~cm}^{-1}$ resolution.
Kinetic modeling has been performed by a ODE23s function of Matlab software.

\section{Results and Discussion}

As foreseen in the introduction section, this paper has been developed in three steps (soaking of UHMWPE in SSF, ageing at $80^{\circ} \mathrm{C}$, and kinetic modeling) described in the following.

\subsection{Study of UHMWPE soaked in SSF at $20-37-100^{\circ} \mathrm{C}$}

In Figure 1 (d) the SSF absorption curves for 420 minutes and at three different temperatures have been plotted. As expected, the diffusion coefficient $D$ improves with increasing the temperature, from $9.4 \bullet 10^{-3} \pm 1,32 \bullet 10^{-4} \mathrm{~mm}^{2} / \mathrm{sec}$ (at room temperature, $\mathrm{p}<0.0001$ ), to $16.4 \cdot 10^{-3} \pm 1.80 \bullet 10^{-4} \mathrm{~mm}^{2} / \mathrm{sec}$, at $37^{\circ} \mathrm{C}$, $\mathrm{p}<0.0001$, and to $19.3 \cdot 10^{-3} \pm 1.79 \cdot 10^{-4} \mathrm{~mm}^{2} / \mathrm{sec}$, at $100^{\circ} \mathrm{C}$, $\mathrm{p}<0.0001$. The differences between all groups are statistically significant $(\mathrm{p}<0.0001)$. As known, liquids or gases can diffuse through the polyethylene bulk after their starting absorption upon the surface; they move towards the polymeric inner part until equilibrium is reached. The diffusion values are those of semi-crystalline synthetic high polymers, although typical diffusion values can vary strongly with fluid concentration [31]. Fukuda in his study evidenced as the polyethylene retained water molecules in the amorphous structure and the water molecules came together forming water clusters of various sizes. The amount of water clustering depended on the water concentration [32].

Klein and Brisco studied the diffusion of linear hydrocarbon or deuteron-carbon molecule through the polyethylene [33]. They highlighted as the amorphous phase of polyethylene is easily accessible for molecules diffusion due to the voids spaces while the crystalline portion is closely packed.

Consequently, $\mathrm{M}_{\infty}$ grows from about $0.8 \%$ to about $1.6 \%$, at $20^{\circ} \mathrm{C}$ and at $100^{\circ} \mathrm{C}$, respectively. The amount of SSF absorbed grows with temperature either because macromolecular chains improve their 

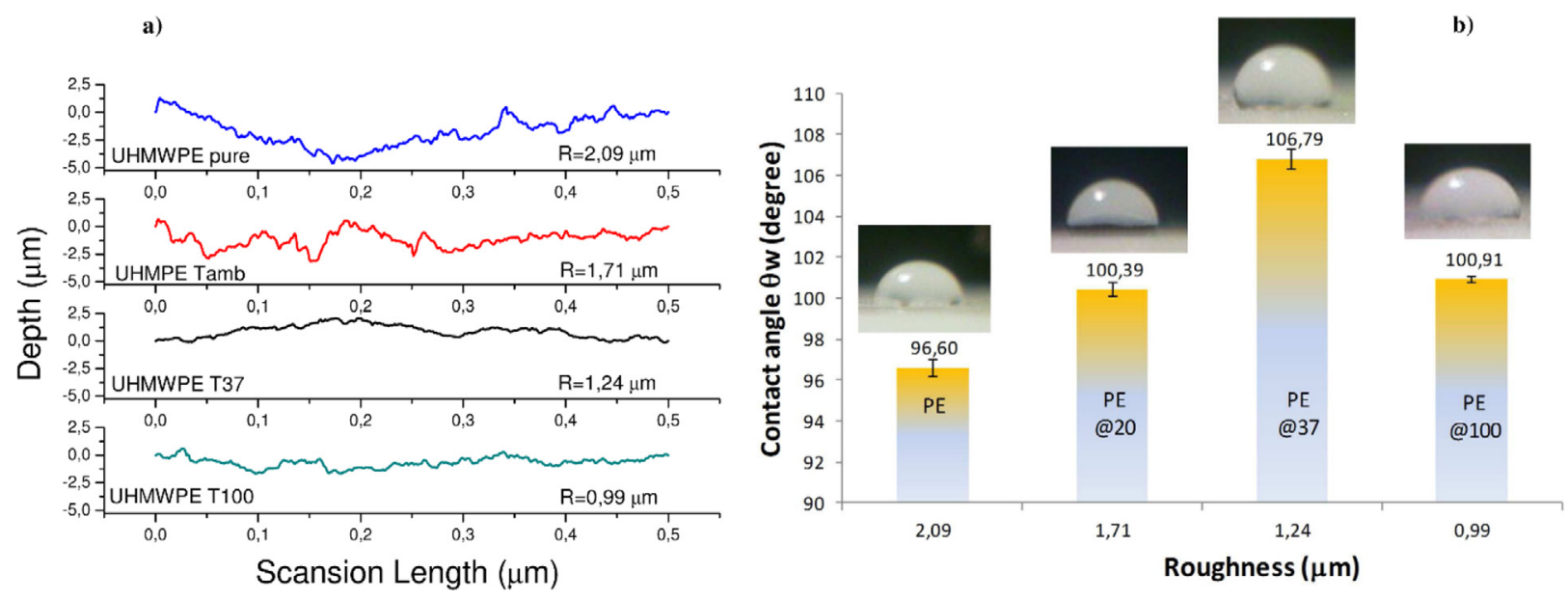

Fig. 2. Roughness (a) and Wenzel contact angle (b) of UH before and after soaking in SSF at $20-37-100^{\circ} \mathrm{C}$.

Table 1

Sample's code, Shore D-Hardness, Young teta value, of UH before and after the soaking in $\mathrm{SSF}$ at $20^{\circ} \mathrm{C}, 37^{\circ} \mathrm{C}$ and $100^{\circ} \mathrm{C}$.

\begin{tabular}{llll}
\hline code & $\begin{array}{l}\text { Soaking } \\
\text { temperature } \\
\left({ }^{\circ} \mathbf{C}\right)\end{array}$ & $\begin{array}{l}\text { Shore D } \\
(\mathbf{H D})\end{array}$ & $\begin{array}{l}\boldsymbol{\theta}_{\mathbf{Y}} \\
(\text { degree } / \mu \mathrm{m})\end{array}$ \\
\hline UH & - & $60.88 \pm 0.08$ & $93 \pm 3$ \\
UH@20 & 20 & $60.46 \pm 0.08$ & $96 \pm 3$ \\
UH@37 & 37 & $60.18 \pm 0.05$ & $104 \pm 5$ \\
UH@100 & 100 & $59.02 \pm 0.08$ & $101 \pm 4$ \\
\hline
\end{tabular}

mobility, especially in the amorphous part of UHMWPE in which SSF can penetrate, or for thermodynamical reasons as illustrated in the case of biodiesel migration into PE [34]. Anyway, SSF reaches its boiling point when test temperature is at about $100^{\circ} \mathrm{C}$ under stirring, so that it partially evaporates from the UHMWPE surface. Thus, the degrading effect of SSF at $100^{\circ} \mathrm{C}$ is lower than expected.

Other authors performed similar weight gain studies on UHMWPE, but the sample's shapes were different since they performed the tests on acetabular cups whose thickness is much higher than that of our samples. For this reason, their test lasted for a bigger period compared to ours test. Affatato et al. studied the weight gain due to fluid absorption (Bovine Calf Serum and water) in different kind sterilized ( $\gamma$-ray, EThylene Oxide (ETO) gas, and unsterilized) UHMWPE acetabular cups, during a period of 60 days. They highlighted as the weight gain changed with the sterilization method and that, it was higher in Bovine Calf serum compared with that in water (in unsterilized samples) [35].

Also L.C. Clarke et al. studied the fluid absorption (water and bovine serum) in conventional UHMWPE and in UHMWPE carbonfiber-reinforced, before and after the sterilization process, and during a period of 150 days [36]. They observed a two phases behavior of weight gain trend, with a little difference in absorption rates between sterilized and unsterilized samples. Their soak rates resulted higher in water compared to serum, contrary to the results of Affatato el al. [35]. In our experimentation, the soaking in SSF for about 7 hours (420 minutes) progressively smooths the polymeric surface with increasing the temperature: as we can see in Figure 2 (a), $R_{z}$ value decreases $2.09 \mu \mathrm{m}$ to $0.99 \mu \mathrm{m}$ at $100^{\circ} \mathrm{C}$. Because of the fluid absorption, polymer starts a slow plasticizing process: Shore $D$ hardness decreases from a value of $60.88 \mathrm{HD}$ in the un-soaked UH, to 59.02 HD in the UH@100 (Table 1).

SSF wettability test has been performed on the un-soaked and soaked samples. The Wenzel contact angle of UHMWPE is higher than $90^{\circ}$, as typical for hydro-phobic material (Figure 2 (b)). Af- ter the soaking at $20^{\circ} \mathrm{C}$ and $37^{\circ} \mathrm{C}$, the hydrophobic character grows even more, arriving to a value of $106.79^{\circ} \mathrm{C}$. Then $\theta_{w}$ decreases to $100.91^{\circ}$ at $100^{\circ} \mathrm{C}$, probably due to the destabilizing action of the high temperature which plasticize the polymeric matrix favoring the droplet insertion within it. For completeness, Young contact angle values are given in details in Table 1, and they follow a similar trend of Wenzel contact angle.

All the analyses above discussed suggested us that at $37^{\circ} \mathrm{C}$ (body temperature) SSF diffuses inside UHMWPE with a rate that is of about $43 \%$ higher than at room temperature $\left(20^{\circ} \mathrm{C}\right)$ and that UHMWPE is still hydrophobic (its wettability is the lowest one among the soaking temperature investigated). Besides, surface hardness at $37^{\circ} \mathrm{C}$ is quite constant, thus UHMWPE still retains its structural integrity after 420 minutes of investigation.

\subsection{Study of oxidation kinetic of UHMWPE soaked in SSF at $37^{\circ} \mathrm{C}$ and aged at $80^{\circ} \mathrm{C}$}

Oxidation kinetic study has been performed on the sample soaked at the temperature of $37^{\circ} \mathrm{C}$ (or UH@37 sample). As it is known from the literature that the natural oxidation of polyethylene could take months or even years to reach appreciable levels of degradation at a body temperature, thermal aging techniques are performed to accelerate the oxidation of UHMWPE [12]. It is therefore assumed that the final properties of the material after accelerated aging are comparable to those that the same naturally aged material would have (long -term effects).

Due to all the considerations above highlighted, the UH@37 was aged in SSF at the temperature of $80^{\circ} \mathrm{C}$, which is the optimal temperature to favor the diffusion of SSF between the polymer chains, avoiding its evaporation (at $\mathrm{T}>100^{\circ} \mathrm{C}$, as already discussed in section 2). Our choice agrees with Eddidin et al. [12], who applied the same temperature of $80^{\circ} \mathrm{C}$ to verify the variation in mechanical strength and wear resistance in gamma-irradiated UHMWPE tibial inserts at this temperature.

To investigate the possible long-term effects related to the presence of SSF within the polymeric matrix, FTIR and GPC analysis have been performed. FTIR spectra of not aged polyethylene samples are given just after soaking in SSF at $37^{\circ} \mathrm{C}$ (UH@37 sample) and compared with control UH sample (pure or un-soaked) (Figure 4a)). The absorption of SSF does not seem to modify the shape of FTIR spectra of UHMWPE and no oxidation process occurs. The same two samples of Figure $4 \mathbf{a}$ ) are also compared after their ageing at $80^{\circ} \mathrm{C}$ in Figure $\left.3 \mathbf{b}\right)$. It must be stressed that ageing durations are not the same but chosen to have comparable maximal absorbances that has been reached after 1930 hours and after 2670 

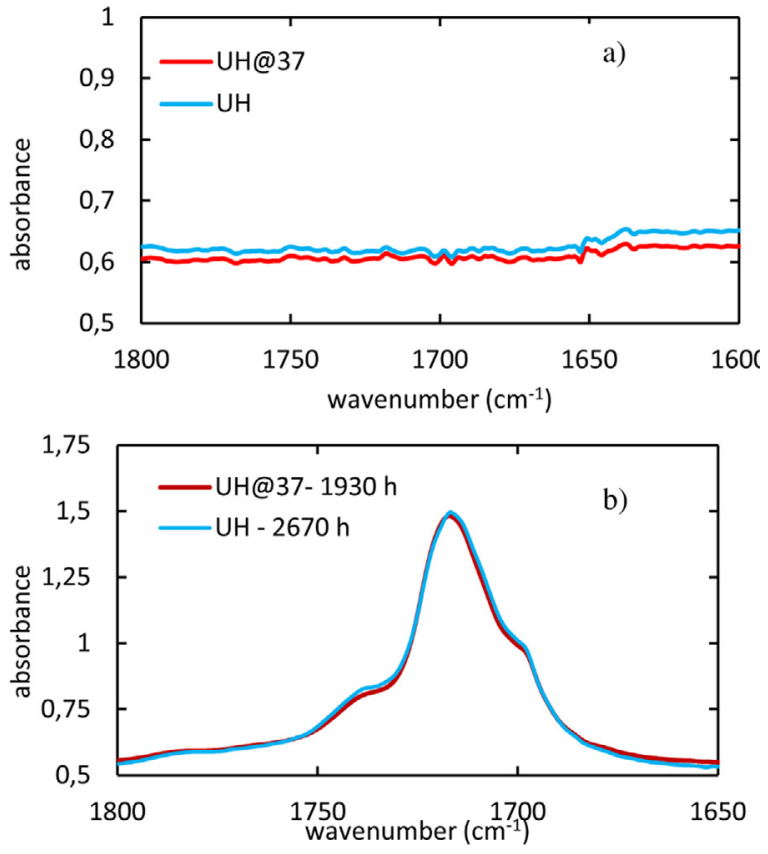

Fig. 3. FTIR spectra in the carbonyl region of pure UH and UH@37 before (a) and after ageing at $80^{\circ} \mathrm{C}(\mathrm{b})$.

hours for the UH@37and UH sample, respectively. All the samples give two peaks: the maxima located at $1717 \mathrm{~cm}^{-1}$ is characteristic of chain ketones and the other at about $1740 \mathrm{~cm}^{-1}$, due to carbonyl species. We must specify that the nature of the carbonyl band is discussed more in details in ref. [37]. The peak at $1717 \mathrm{~cm}^{-1}$ is in fact the overall of these at $1713 \mathrm{~cm}^{-1}$ and $1720 \mathrm{~cm}^{-1}$ for carboxylic acids and ketones, respectively. The peak at about $1717 \mathrm{~cm}^{-1}$ has a shoulder at about $1700 \mathrm{~cm}^{-1}$. This graph, compared with that of Figure 3a), suggests that the ageing at $80^{\circ} \mathrm{C}$ induces an oxidation/degradation process not still activated at room temperature. Here also, the presence of SSF does not induce the appearance of any shoulder ascribed to oxidation products of SSF.

Absorbances were thus converted into concentrations by Bert Lambert law using $300 \mathrm{l} \mathrm{mol}^{-1} \mathrm{~cm}^{-1}$ as molar absorptivity for carbonyls [38]. Results are given in Figure 4.

Curves are shifted to the short duration times for UH soaked with SSF (UH@37 sample).

This suggest two possible situations: SSF oxidize very fast or induce the oxidation of polyethylene chains (identically to a previous study of polyethylene in contact with biodiesels [39]).

In the first case (SSF oxidized), it means that SSF will generate oxidation products (also detectable in the carbonyl region). Those later are not necessarily the same than those of UH; thus, FTIR spectra would be the simple overlapping of UH and SSF oxidation products with a global shape depending of SSF concentration in polyethylene.

In the second case (polyethylene oxidation), SSF favors the oxidation of $\mathrm{UH}$ and the appearance of usual compounds due to polyethylene oxidation, but at a higher rate. Let us note that the matter that FTIR spectra of oxidized sample are the same for pure UH, and UH samples soaked with SSF (or UH@37 sample, see Figure 3 (b)), militates in favor of the second hypothesis.

To confirm this last scenario (that is what SSF favors the oxidation of UH), Gel Permeation Chromatography were performed on aged samples. It was first verified that chromatograms are the same for SSF soaked samples before and after an acetonitrile extraction. Figure 5 displays the changes in average weight molar mass, this later being linked to polyethylene embrittlement [40].
According to Figure 4, the molar mass decreases faster for PE soaked with SSF (UH@37 sample). In other words, the SSF oxidize some radicals can favor the oxidation of polyethylene chains.

Interestingly, one sees from Figure 4 and 5 that the impregnation of SSF in pure UH leads to a decrease of induction period by a factor 2. According to Colin et al. [41], the induction period would obey an Arrhenius law with an apparent activation energy close to $116 \mathrm{~kJ} \mathrm{~mol}^{-1}$. Using this value, it suggests that the immersion of $1.0 \%$ of SSF would correspond to an ageing at a fictive equivalent temperature of $86^{\circ} \mathrm{C}$ instead of $80^{\circ} \mathrm{C}$.

\subsection{Kinetic modelling}

Finally, to better describe the phenomena (depicted in Figure 4), we decided to run simulations based on kinetic modeling approach. It has actually been established for years that the oxidation of polyethylene grades (including biomedical grade UHMWPE) can be simulated using a mechanistic scheme derived from the Basic Autoxidation Scheme proposed by Bolland and coworkers [45], but with a supplementary assumption that at moderate temperature, the main radical's source is the decomposition of hydroperoxides $(\mathrm{POOH})$. In the case of polyethylene [41,44], the kinetic model is given in Table 2 where:

- $\mathrm{P}^{\circ}, \mathrm{POO}^{\circ}, \mathrm{POOH}, \mathrm{PO}^{\circ}$ are respectively alkyl, peroxy, hydroperoxides, alkoxyl radicals, $\mathrm{PH}$ represent the reactive $\mathrm{C}-\mathrm{H}$ (methylene groups), $\mathrm{P}=\mathrm{O}$ the carbonyls products.

- ki and the rate constants and g1 the yield of carbonyl formation from hydroperoxides decomposition.

- the initiation reaction $1 \mathrm{u}$ and $1 \mathrm{~b}$ actually are the kinetically equivalent representation of an in-chain process where hydroperoxides first generate $\mathrm{PO}^{\circ}$ by a slow process and $\mathrm{PO}^{\circ}$ rapidly decompose into carbonyls or alcohols together with the generation of alkyl radicals.

“"This scheme is converted into a differential system. This one is numerically solved using the kinetic parameters given in Table 2 and the following boundaries conditions, which were discussed in [44,45]:" At $\mathrm{t}=0,\left[\mathrm{P}^{\circ}\right]_{0}=\left[\mathrm{POO}^{\circ}\right]_{0}=0=\left[\mathrm{PO}^{\circ} \mathrm{OP}\right]_{\text {cage } 0}=0$, $[\mathrm{POOH}]_{0}=10^{-4} \mathrm{~mol} \mathrm{l}^{-1}$ and $[\mathrm{PH}]=60 \mathrm{~mol} \mathrm{l}^{-1}$, and $\left[\mathrm{O}_{2}\right]=\mathrm{s}_{\mathrm{O} 2} \times \mathrm{P}_{\mathrm{O} 2}, \mathrm{P}_{\mathrm{O} 2}$ being the partial oxygen pressure and $\mathrm{s}_{\mathrm{O} 2}$ the oxygen solubility in amorphous phase of PE: $\mathrm{s}_{\mathrm{O} 2}=1.8 \times 10^{-8}$ mol l-1 $\mathrm{MPa}^{-1}$ [43].

The solution of differential system gives the changes in reactive species $\left(\mathrm{P}^{\circ}, \mathrm{POO}^{\circ}, \mathrm{POOH},\left[\mathrm{PO}^{\circ} \mathrm{OP}\right]_{\text {cage } \ldots)}\right.$ ) from which the changes in carbonyls can be predicted by:

$$
\begin{aligned}
\frac{d[P=O}{d t}= & \gamma_{1} \boldsymbol{k}_{1 u}[\mathrm{POOH}]+\gamma_{1} \boldsymbol{k}_{1 b}[\mathrm{POOH}]^{2}+\boldsymbol{k}_{62}\left[\mathrm{PO}^{\circ} \mathrm{OP}\right]_{\text {cage }} \\
& +2 \boldsymbol{\gamma}_{1} \boldsymbol{k}_{63}\left[\mathrm{PO}^{\circ} \mathrm{OP}\right]_{\text {cage }}
\end{aligned}
$$

At first, for adjusting simulations for the "pure" UHMWPE, $\mathrm{k}_{1 \mathrm{u}}$ must have been lowered to $5.10^{-10} \mathrm{~s}^{-1}$ instead of $1.6 \times 10^{-8}$ $\mathrm{s}^{-1}$ presumably for describing the specificity of UHMWPE compared to HDPE studied in ref [43]. It can actually be assumed that UHMWPE differs from other PE's for general purposes by the choice of organometallic catalysts, those latter directly influencing the rate of unimolecular hydroperoxides decomposition [42]. It remains now to find how adapting this model to the case of PE impregnated with SSF i.e. with some HA molecules. For that purpose, several scenarii were tested and will be discussed here below.

Hypothesis 1. SSF is considered as an unstable impurity. This can be computed as an initial quantity of unstable defects (written as $[\mathrm{POOH}]_{0}$ ). Some simulations (for varying concentrations in SSF) are given in Figure 6 (blue curve is pure PE case) where $[\mathrm{POOH}]_{0}$ was increased up to $0.1 \mathrm{~mol} \mathrm{l}^{-1}$ i.e. the order of magnitude of concentration in "monomeric" units of SSF after $37^{\circ} \mathrm{C}$ impregnation. 


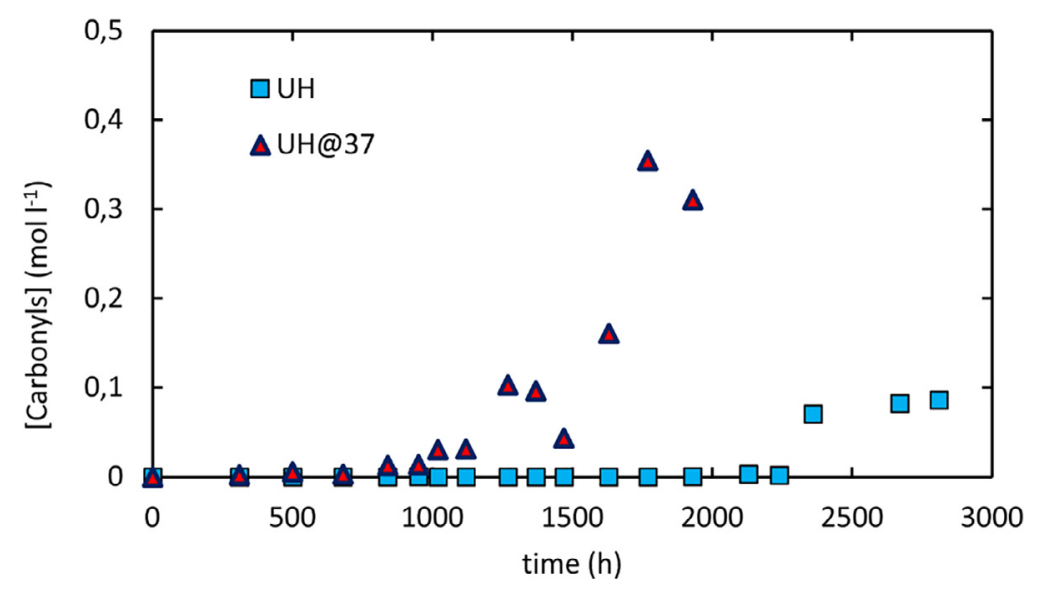

Fig. 4. Kinetic curves for carbonyl build-up of pure UH and UH@37 after ageing at $80^{\circ} \mathrm{C}$.

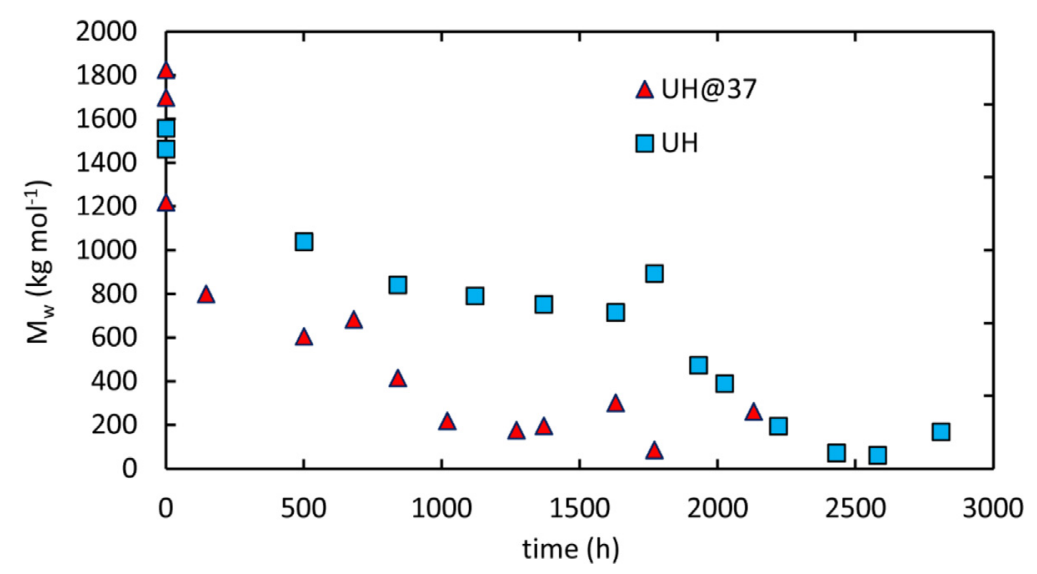

Fig. 5. Molar mass changes of pure UH and UH@37 after ageing at $80^{\circ} \mathrm{C}$.

Table 2

Reaction and Rate constant values used for simulations.

\begin{tabular}{llll}
\hline Reaction & Rate constant & Value at 80 & \\
\hline $\mathrm{POOH} \rightarrow 2 \mathrm{P}^{\circ}+\gamma_{\mathrm{CO}} \mathrm{PC}=\mathrm{O}+\gamma_{\mathrm{s}} \mathrm{S}$ & $\mathrm{k}_{1 \mathrm{u}}$ & $1.6 \bullet 10^{-8(*)}$ & $\mathrm{s}^{-1}$ \\
$\mathrm{POOH}+\mathrm{POOH} \rightarrow \mathrm{P}^{\circ}+\mathrm{POO}^{\circ}+\gamma_{\mathrm{CO}} \mathrm{PC}=\mathrm{O}+\gamma_{\mathrm{s}} \mathrm{s}$ & $\mathrm{k}_{1 \mathrm{~b}}$ & $7.9 \bullet 10^{-7}$ & $1 \mathrm{~mol}^{-1} \mathrm{~s}^{-1}$ \\
$\mathrm{P}^{\circ}+\mathrm{O}_{2} \rightarrow \mathrm{POO}{ }^{\circ}$ & $\mathrm{k}_{2}$ & $1.0 \bullet 10^{8}$ & $1 \mathrm{~mol}^{-1} \mathrm{~s}^{-1}$ \\
$\mathrm{POO}^{\circ}+\mathrm{PH} \rightarrow \mathrm{POOH}+\mathrm{P}^{\circ}$ & $\mathrm{k}_{3}$ & 0.243 & $1 \mathrm{~mol}^{-1} \mathrm{~s}^{-1}$ \\
$\mathrm{P}^{\circ}+\mathrm{P}^{\circ} \rightarrow$ inactive products & $\mathrm{k}_{4}$ & $8.0 \bullet 10^{11}$ & $1 \mathrm{~mol}^{-1} \mathrm{~s}^{-1}$ \\
$\mathrm{P}^{\circ}+\mathrm{POO}^{\circ} \rightarrow$ inactive products & $\mathrm{k}_{5}$ & $2.3 \bullet 10^{11}$ & $1 \mathrm{~mol}^{-1} \mathrm{~s}^{-1}$ \\
$\mathrm{POO}^{\circ}+\mathrm{POO}{ }^{\circ} \rightarrow\left[\mathrm{PO}{ }^{\circ} \mathrm{OP}\right]_{\text {cage }}+\mathrm{O}_{2}$ & $\mathrm{k}_{60}$ & $6.1 \bullet 10^{8}$ & $1.0 \bullet 10^{6}$ \\
{$\left[\mathrm{PO}^{\circ}+{ }^{\circ} \mathrm{OP}\right]_{\text {cage }} \rightarrow \mathrm{POOP}$} & $\mathrm{k}_{61}$ & $2.4 \bullet 10^{5}$ & $\mathrm{~s}^{-1}$ \\
{$\left[\mathrm{PO}^{\circ}+{ }^{\circ} \mathrm{OP}\right]_{\text {cage }} \rightarrow \mathrm{POH}+\mathrm{PC}=\mathrm{O}$} & $\mathrm{k}_{62}$ & $\mathrm{~s}^{-1}$ \\
{$\left[\mathrm{PO}^{\circ}+{ }^{\circ} \mathrm{OP}\right]_{\text {cage }} \rightarrow 2 \mathrm{P}^{\circ}+2 \gamma_{\mathrm{CO}} \mathrm{PC}=\mathrm{O}+2 \gamma_{\mathrm{s}} \mathrm{s}$} & $\mathrm{k}_{63}$ & $1.2 \bullet 10^{6}$ & $\mathrm{~s}^{-1}$ \\
\hline
\end{tabular}

$\left({ }^{*}\right)$ indicates the value reported in ref. [43]adjusted for better describing the ageing kinetics of UHMWPE (see text).

The model describes a severe drop in induction period, but the validation of such a scenario required to follow the ageing of SSF "alone" in the conditions under investigation $\left(80^{\circ} \mathrm{C}\right)$ and determine if SSF is quickly converted into radical species.

Hypothesis 2. since SSF contains $\mathrm{COOH}$ groups, those latter can destabilize polyethylene hydroperoxides which could decompose either by an unimolecular or a bimolecular decomposition process [46-48]:

$\mathrm{POOH} \rightarrow \mathrm{PO}^{\circ}+\mathrm{OH}^{\circ} \mathrm{k}_{\text {unimolecular }}$

$\mathrm{POOH}+\mathrm{POOH} \rightarrow \mathrm{PO}^{\circ}+\mathrm{POO}^{\circ}+\mathrm{H}_{2} \mathrm{O} \mathrm{k}_{\text {bimolecular }}$
In presence of hydrogen bonding species (carboxylic acids, alcohols or water), the decomposition of $\mathrm{POOH}$ can be accelerated which can be described by a supplementary reaction $[46,49]$ :

$\mathrm{POOH}+\mathrm{SSF}-\mathrm{COOH} \rightarrow \mathrm{PO}^{\circ}+\mathrm{H}_{2} \mathrm{O}+\mathrm{SSF}^{-\mathrm{COO}^{\circ} \mathrm{k}_{\text {catalyzed }}}$

and $\mathrm{SSF}-\mathrm{COO}^{\circ}$ attacks another PE chain later.

The unimolecular decomposition and bimolecular decompositions correspond to $1 \mathrm{u}$ and $1 \mathrm{~b}$ reactions in model (Table 2 ).

Figure 7 depicts the kinetic modeling of oxidation with a SSF concentration also derived from the concentration of hydroxyl are carboxylic acids hold by SSF groups $\left(0.15 \mathrm{~mol} \mathrm{l}^{-1}\right)$. The rate constant $\mathrm{k}_{\text {catalyzed }}$ was fixed to $4.10^{-7} 1 \mathrm{~mol}^{-1} \mathrm{~s}^{-1}$. The matter that the order of magnitude is comparable to those of $k_{1 b}$ is for us an encouraging argument. It is thus possible to consider this scenario as possible, but its validation requires to investigate the stability of 


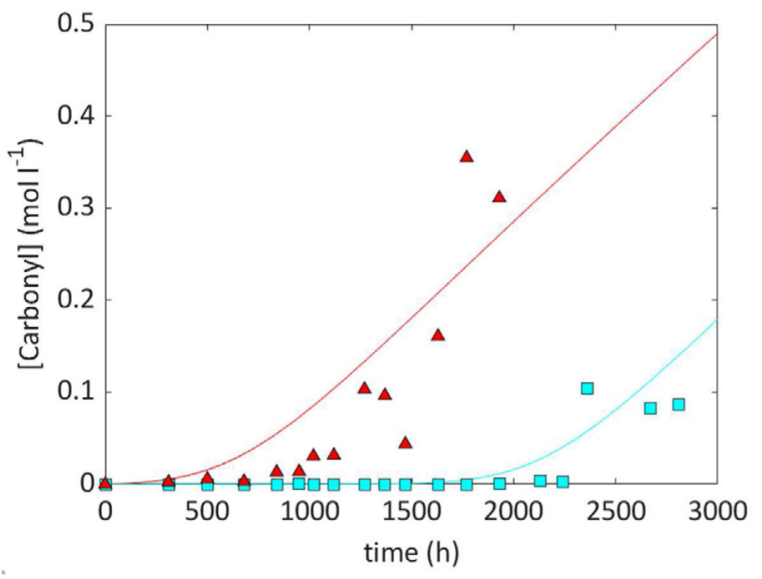

Fig. 6. Kinetic modeling of carbonyl build up at $80^{\circ} \mathrm{C}$ under air as for hypothesis 1: various initial concentration in unstable groups: $[\mathrm{POOH}] 0=0.0001$ and $0.15 \mathrm{~mol}$ $\mathrm{l}^{-1}$ for red and blue curve, respectively.

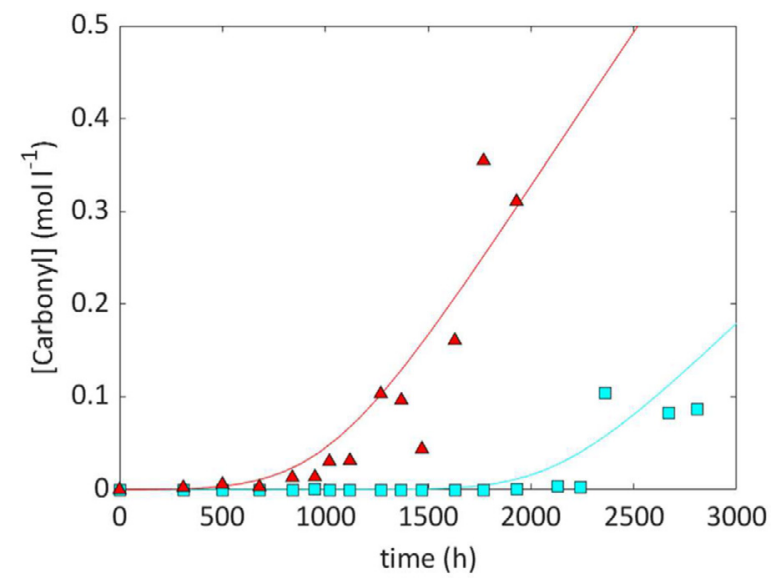

Fig. 7. Kinetic modeling of carbonyl build up at $80^{\circ} \mathrm{C}$ under air as for hypothesis (Hp) 1 and 2 together: $[\mathrm{POOH}]_{0}=0.0001 \mathrm{~mol} \mathrm{l}^{-1}$, for red curve (Hp.1); [SSF$\mathrm{COOH}]=0.15 \mathrm{~mol} \mathrm{l}^{-1}(\mathrm{Hp} 1)$, with added catalyzed $\mathrm{POOH}$ decomposition (kcatalyzed $=4.10^{-7} 1 \mathrm{~mol}^{-1} \mathrm{~s}^{-1}$ at $80^{\circ} \mathrm{C}$ ) for blue curve (Hp.2).

"polyethylene like" hydroperoxides in presence of SSF. Quantification of hydroperoxides (performed such as [50]) and investigation of their stability in presence of SSF would thus be important but it is for us a prospective work.

Hypothesis 3. A third scenario is possible and involves a true cooxidation between SSF and polyethylene. SSF oxidizes since this compound displays at least two kinds of $\mathrm{C}-\mathrm{H}$ being particularly oxidizable: $\mathrm{C}-\mathrm{H}$ in $\alpha$-position of ether groups and $\mathrm{C}-\mathrm{H}$ in $\alpha$ position of $\mathrm{NH}$ functions holded by amide groups. The oxidation of these latter creates radicals (denoted her by $\mathrm{SSF}^{\circ}, \mathrm{SSF}_{-} \mathrm{OO}^{\circ} . .$. meaning that they are hold by SSF molecules). some of them can attack polyethylene chains which generates other radicals $\left(\mathrm{P}^{\circ}, \mathrm{POO}^{\circ} \ldots\right)$. The complete kinetic model is thus:

(1 $\left.\mathrm{u}^{\prime}\right) \mathrm{SSF}-\mathrm{OOH} \rightarrow 2 \mathrm{SSF}^{\circ}+\gamma_{1} \mathrm{SSF}=\mathrm{O} \quad \mathrm{k}_{1 \mathrm{u}^{\prime}}$

(1 $\left.\mathrm{b}^{\prime}\right) \mathrm{SSF}-\mathrm{OOH}+\mathrm{SSF}-\mathrm{OOH} \rightarrow \mathrm{SSF}^{\circ}+\mathrm{SSF}-\mathrm{OO}^{\circ}+\gamma_{1}{ }^{\prime} \mathrm{SSF}=\mathrm{O} \quad \mathrm{k}_{1 \mathrm{~b}^{\prime}}$

(2') $\mathrm{SSF}^{\circ}+\mathrm{O}_{2} \rightarrow{\mathrm{SSF}-\mathrm{OO}^{\circ}}^{\circ} \mathrm{k}_{2}$ '

(3') $\mathrm{SSFOO}^{\circ}+\mathrm{SSFH} \rightarrow \mathrm{SSFOOH}+\mathrm{SSF}^{\circ} \quad \mathrm{k}_{3}$ '

(4') $\mathrm{SSF}^{\circ}+\mathrm{SSF}^{\circ} \rightarrow$ inactive products $\quad \mathrm{k}_{4}$,

(5') $\mathrm{SSF}^{\circ}+\mathrm{SSFOO}^{\circ} \rightarrow$ inactive products $+\left(1-\gamma_{5},\right) \mathrm{SSFOOH} \quad \mathrm{k}_{5}$,

(6') $\mathrm{SSFOO}^{\circ}+\mathrm{SSFOO}^{\circ} \rightarrow$ inactive products $\quad \mathrm{k}_{6}$ '

Together with " crossed reactions " for initiation:

(1b") SSF-OOH $+\mathrm{P}-\mathrm{OOH} \rightarrow \alpha \mathrm{SSF}^{\circ}+(1-\alpha) \mathrm{PE}^{\circ}+$

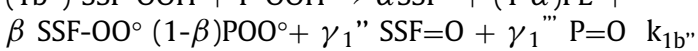

For propagation:

(3") $\mathrm{SSF}-\mathrm{OO}^{\circ}+\mathrm{PH} \rightarrow \mathrm{SSFOOH}+\mathrm{P}^{\circ} \mathrm{k}_{3}$ "

(3"') $\mathrm{P}-\mathrm{OO}^{\circ}+\mathrm{SSF} \rightarrow \mathrm{POOH}+\mathrm{SSF}^{\circ} \quad \mathrm{k}_{3}$ "'

And many crossed termination reactions:

$\mathrm{P}^{\circ}+\mathrm{SSF}^{\circ} \rightarrow$ inactive products $\quad \mathrm{k}_{4}$ "

$\mathrm{P}^{\circ}+\mathrm{SSFOO}^{\circ} \rightarrow$ inactive products $\mathrm{k}_{5}$ "

$\mathrm{POO}^{\circ}+\mathrm{SSF}^{\circ} \rightarrow$ inactive products $\quad \mathrm{k}_{5}$ "'

$\mathrm{SSFOO}^{\circ}+\mathrm{POO}^{\circ} \rightarrow$ inactive products $\mathrm{k}_{6}$ "

Such models were already computed in the past [39]. They involve a great number of adjustable parameters. Some of the missing constants can be arbitrarily fixed for example using relations such as: $\mathrm{k}_{1 \mathrm{~b}}{ }^{\prime}=\left(\mathrm{k}_{1 \mathrm{~b}} \times \mathrm{k}_{1 \mathrm{~b}^{\prime}}\right)^{2}$ or $\mathrm{k}_{3}=\mathrm{k}_{3^{\prime}}$ and $\mathrm{k}_{3^{\prime}}=\mathrm{k}_{3}{ }^{\prime \prime}$. However, it remains to first understand the oxidation of pure SSF (to determine the rate constants $k_{1 u^{\prime}}, k_{1 b^{\prime}} \ldots . . k_{5^{\prime}}, k_{6}$ ) which goes out of the scope of the present paper. In other words, scenario 1 and 2 allow, despite their apparent simplicity, to catch the main effect of SSF on polyethylene oxidation.

In principle, the estimation of rate constants at other temperatures than $80^{\circ} \mathrm{C}$ (for instance 100 and $120^{\circ} \mathrm{C}$ ) and their extrapolation at $37^{\circ} \mathrm{C}$ would then make possible to predict the oxidation kinetics for in vivo conditions. It remains however first to fully validate the mechanistic interpretation of SSF effect proposed in this paper.

\section{Conclusion}

This study investigated the surface effects of the SSF diffusion (at different soaking temperatures) in biomedical grade Ultra High Molecular Weight Polyethylene (UHMWPE). The kinetic analysis of the oxidation mechanism has been performed on the UHMWPE soaked in SSF at $37^{\circ} \mathrm{C}$ (body temperature); its long-term thermal stability was investigated from ageing at $80^{\circ} \mathrm{C}$. Finally, a kinetic model was shown to theoretically reproduce the degradation mechanisms induced by SSF on UHMWPE aged at $80^{\circ} \mathrm{C}$.

Experimental results highlighted as:

$\sqrt{ }$ SFF smooths the polymer's surface, generally increasing its wettability (until $37^{\circ} \mathrm{C}$ ) and that surface hardness changes slowly, so that at $37^{\circ} \mathrm{C}$ is quite close to that of unsoaked sample (or control sample).

$\checkmark \sqrt{ }$ The presence of SSF accelerates the oxidation of polyethylene which produces oxidized groups and the consequent change in the average molecular weight. This means that SSF causes the creation of radical species within the polyethylene during the aging time at $80^{\circ} \mathrm{C}$. Without the aging process, the degradation does not trigger because it is precisely the temperature of $80^{\circ} \mathrm{C}$ that facilitates the loosening of the macromolecular chains and the penetration of SSF into the polyethylene. SSF causes the destruction of carbon-hydrogen and/or carbon-carbon bonds with the consequent oxidation of the material. Thus, SSF degrades polyethylene by a factor of 2 at the aging temperature of $80^{\circ} \mathrm{C}$, leading to a significant decrease in molecular weight.

$\sqrt{ }$ A kinetic model was established: it simulates the accelerating effect of SSF by considering that the polar groups in SSF, destabilize hydroperoxides formed in polyethylene after its oxidation.

Studies are in progress to repeat this same investigation on the nanocomposites made by UHMWPE and nanofillers capable to improve its wear resistance [22,24]. It will be conducted with the simulated synovial fluid at an aging temperature not only of $80^{\circ} \mathrm{C}$ but also below $80^{\circ} \mathrm{C}$, to define the threshold temperature necessary for the synovial fluid to accelerate the normal degradation of UHMWPE. Furthermore, the investigation must be improved with the use of a bovine calf serum (also containing the protein molecules, absent in the simulated synovial fluid used here), to separate the specific effect of proteins action. 
Many previous studies, also carried out by our research group $[11,12,51]$, have shown that the oxidative degradation of joint prostheses is linked to free radicals that are generated in the PE during the sterilization or cross-linking phase. The PE sample used in this study was not irradiated and may not contain free radicals. Therefore, in a forthcoming experiment, the accelerating effect of free radicals in the oxidation of $\mathrm{PE}$ and the consequent changes to be made in the modeling will also be evaluated.

\section{Author Contributions}

Conceptualization: AV, ER; Data curation: AV, ER, CS; Formal analysis ER and CS; Investigation: AV, ER, CS; Methodology: AV, ER; Supervision: AV; Validation: AV, ER, CS; Visualization: AV, ER, CS; Roles/Writing - original draft AV, ER, CS; Writing - review \& editing AV, ER, CS.

\section{Declaration of Competing Interest}

There are no conflicts of interest to declare.

\section{References}

[1] A. Subic, J. Kovacs, Design and Materials in Snowboarding, in: A. Subic (Ed.), Mater. Sport. Equip., 2nd Editio, Elsevier, 2019: pp. 281-296. 10.1016/B978-008-102582-6.00009-5.

[2] P. Bracco, A. Bellare, A. Bistolfi, S. Affatato, Ultra-High Molecular Weight Polyethylene: Influence of the Chemical, Physical and Mechanical Properties on the Wear Behavior. A Review 10 (2017) 791 Materials (Basel)., doi:10.3390/ ma10070791.

[3] M. Fejdyś, M. Łandwijt, A. Kucharska-Jastrząbek, M.H. Struszczyk, The Effect of Processing Conditions on the Performance of UHMWPE-Fibre Reinforced Polymer Matrix Composites, FIBRES Text. East. Eur. 24 (2016) 112-120, doi:10.5604/ 12303666.1201140.

[4] P. Montois, V. Nassiet, J.A. Petit, D. Adrian, Viscosity effect on epoxydiamine/metal interphases-Part II: Mechanical resistance and durability, Int. J. Adhes. Adhes. 27 (2007) 145-155, doi:10.1016/j.ijadhadh.2006.03.001.

[5] B. de Nève, M.E.R. Shanahan, Effects of humidity on an epoxy adhesive, Int. J. Adhes. Adhes. 12 (1992) 191-196, doi:10.1016/0143-7496(92)90053-X.

[6] S. Ge, X. Kang, Y. Zhao, One-year biodegradation study of UHMWPE as artificial joint materials: variation of chemical structure and effect on friction and wear behavior, Wear 271 (2011) 2354-2363, doi:10.1016/j.wear.2010.11.048.

[7] S. Yousef, A.M. Visco, G. Galtieri, D. Nocita, C. Espro, Wear behavior of UHMWPE reinforced by carbon nanofiller and paraffin oil for joint replacement, Mater. Sci. Eng. C. 73 (2017) 234-244, doi:10.1016/j.msec.2016.11.088.

[8] A.M. Visco, S. Yousef, G. Galtieri, D. Nocita, J. Njuguna, Thermal, Mechanical and Rheological behaviors of nanocomposites based on UHMWPE/Paraffin Oil/Carbon Nano filler obtained by using different dispersion techniques, JOMSpringer 68 (2016) 1078-1089, doi:10.1007/s11837-016-1845-X.

[9] L. Costa, P. Bracco, Mechanisms of Cross-Linking, in: S. Kurtz (Ed.), Oxidative Degradation, and Stabilization of UHMWPE, UHMWPE Biomater. Handb., 2016, pp. 467-487, doi:10.1016/B978-0-323-35401-1.00026-0. Edn.d.

[10] C.M. Rimnac, A.H. Burstain, R.W.K.J.M. Carr, W.T.M.F. Betts, Chemical and mechanical degradation of UHMWPE: Report of the development of an in vitro test. J. Appl. Biomat. 5 (1994) 17-21.

[11] A. Visco, N. Campo, V. Brancato, M. Trimarchi, Influence of a-Tocopherol Load and Annealing Treatment on the Wear Resistance of Biomedical UHMWPE Irradiated with Electron Beam, Int. J. Polym. Anal. Charact. 18 (2013) 545-556, doi:10.1080/1023666X.2013.819545.

[12] A.A. Eddidin, C.W. Jewett, A. Kalinowski, K. Kwarteng, S.M. Kurtz, Degradation of mechanical behavior in UHMWPE after natural and accelerated aging, Biomaterials 21 (2000) 1451-1460, doi:10.1016/s0142-9612(00)00021-1.

[13] P. Eyerer, Y.K. Ke, Property changes of UHMW polyethylene hip cup endoprostheses during implantation, J. Biomed. Mater. Res. 18 (1984) 1137-1151, doi: $10.1002 / \mathrm{jbm} .820180915$

[14] M.S. Jahan, C.W.G. Schwartz, J.A. Davidson, Combined chemical and mechanical effects on free radicals in UHMWPE joints during implantation, J. Biomed. Mat. Res. 25 (1991) 1005-1017, doi:10.1002/jbm.820250807.

[15] L. Costa, P. Bracco, E.B. del Prever, M.P. Luda, L. Trossarelli, Analysis of products diffused into UHMWPE prosthetic components in vivo, Biomaterials 22 (2001) 307-315, doi:10.1016/S0142-9612(00)00182-4.

[16] M. Chandrasekaran, L.Y. Wei, K.K. Venkateshwaran, A.W. Batchelor, N.L. Loh, Tribology of UHMWPE tested against a stainless steel counterface in unidirectional sliding in presence of model synovial fluids: part 1, Wear 223 (1998) 13-21, doi:10.1016/S0043-1648(98)00294-4.

[17] S.P. James, S. Blazka, E.W. Merrill, M. Jasty, K.R. Lee, C.R. Bragdon, W.H. Harris, Challenge to the concept that UHMWPE acetabular components oxidize in vivo, Biomaterials 14 (1993) 643-647, doi:10.1016/0142-9612(93)90062-7.

[18] E. Oral, B.W. Ghali, A. Neils, O.K. Muratoglu, A new mechanism of oxidation in ultrahigh molecular weight polyethylene caused by squalene absorption, J.
Biomed. Mater. Res. B Appl. Biomater. 100 (2012) 742-751, doi:10.1002/jbm.b. 32507.

[19] H. Sakoda, S. Niimi, Impact of lipid-induced degradation on the mechanical properties of ultra-high molecular weight polyethylene for joint replacements, J. Mech. Behav. Biomed. Mater. 53 (2016) 218-225.

[20] M.P. Gispert, A.P. Serro, R. Colaço, B. Saramago, Friction and wear mechanisms in hip prosthesis: Comparison of joint materials behaviour in several lubricants, Wear 260 (2006) 149-158, doi:10.1016/j.wear.2004.12.040.

[21] E.A. Balazs, D. Watson, I.F. Duff, S. Roseman, Hyaluronic acid in synovial fluid. I. Molecular parameters of hyaluronic acid in normal and arthritis human fluids, Arthritis Rheumatol 10 (1967) 357-376, doi:10.1002/art.1780100407.

[22] Y. Yan, A. Neville, D. Dowson, Biotribocorrosion of CoCrMo orthopaedic implant materials-Assessing the formation and effect of the biofilm, Tribol. Int. 40 (2007) 1492-1499, doi:10.1016/j.triboint.2007.02.019.

[23] T. Kokubo, H. Takadama, How useful is SBF in predicting in vivo bone bioactivity? Biomaterials 27 (2006) 2907-2915, doi:10.1016/j.biomaterials.2006.01.017.

[24] A. Visco, S. Yousef, C. Scolaro, C. Espro, M. Cristani, Tribological behavior of nanocomposites based on UHMWPE aged in simulated synovial fluid, Polymers (Basel) 10 (2018), doi:10.3390/polym10111291

[25] G.B. Cornwall, C.M. Hansson, J.T.Bryant A.J.Bowe, Surface degradation features and microstructural properties of ultra-high molecular weight polyethylene (UHMWPe), J. Mater. Sci. Mater. Med. 8 (1997) 303-309, doi:10.1023/A: 1018564412753.

[26] S. Yousef, A. Visco, G. Galtieri, D. Nocita, C. Espro, Wear behaviour of UHMWPE reinforced by carbon nanofiller and paraffin oil for joint replacement, Mater. Sci. Eng. C. 73 (2017) 234-244, doi:10.1016/j.msec.2016.11.088.

[27] A.M. Visco, N. Campo, P. Cianciafara, Comparison of seawater absorption properties of thermoset resins based composites, Compos. A. 42 (2010) 123-130, doi:10.1016/j.compositesa.2010.10.009.

[28] Abraham Marmur, Chapter Part1: Fundamental Aspects. A Guide to the Equilibrium Contact Angles Maze, in: K.L. Mittal (Ed.), Contact Angle, Wettability Adhes., Koninklijke Brill NV, Leiden, 2009, pp. 3-18.

[29] R.N. Wenzel, Resistance of solid surfaces to wetting by water, Ind. Eng. Chem. 28 (1936) 988-994, doi:10.1021/ie50320a024.

[30] C. Gabriel, E. Kokko, B. Löfgren, J. Seppälä, H. Münstedt, Analytical and rheologicalcharacterization of long-chainbranchedmetallocenecatalyzedethylenehomopolymers, Polymer (Guildf) 43 (2002) 6383-6390, doi:10.1016/S0032-3861(02)00564-5.

[31] E.L. Cussler, Diffusion mass transfer in fluid systems, in: C.U. Press (Ed.), Third Edit, The Edinburgh Building, Cambridge CB2 8RU, UK, 2009.

[32] M. Fukuda, Clustering Of Water In Polyethylene: A Molecular-Dynamics Simulation, J. Chem. Phys. 109 (1998) 6476, doi:10.1063/1.477293.

[33] J. Klein, B.J. Briscoe, The Diffusion Of Long-Chainmolecules through Bulk Polyethylene, Proc. R. Soc. Lond. A. Math. Phys. Sci. 365 (1979) 53-73.

[34] E. Richaud, B. Flaconnèche, J. Verdu, Biodiesel permeability in polyethylene, Polym. Test. 31 (2012) 1070-1076, doi:10.1016/j.polymertesting.2012.08.003.

[35] S. Affatato, C. Vandelli, B. Bordini, A. Toni, Fluid absorption study in ultrahigh molecular weightpolyethylene (UHMWPE) sterilized and unsterilized acetabular cups, Roc Inst Mech Eng H 215 (2001) 107-111, doi:10.1243| 0954411011533463

[36] L.C. Clarke, P.Hosseinian W.Starkebaum, M. Guiraen, R. Okuda, R. Salovey, R. Young, Fluid-sorption phenomena in sterilized polyethylene acetabular prostheses, Biomaterials 6 (1985) 184-188, doi:10.1016/0142-9612(85)90007-9.

[37] M. Gardette, A. Perthue, J.-L. Gardette, T. Janecska, E. Földes, B. Pukánszky, S. Therias, Photo- and thermal-oxidation of polyethylene:Comparison of mechanisms and influence of unsaturation content, Polym. Degrad. Stab. 98 (2013) 2383-2390, doi:10.1016/j.polymdegradstab.2013.07.017

[38] F.M. Rugg, J.J. Smith, R.C. Bacon, Infrared spectrophotometric studies on polyethylene. II. Oxidation, J. Polym. Sci. 13 (154AD) 535-547. 10.1002/pol.1954.120137202.

[39] B.Fayolle Richaud, J. Verdu, J. Rychlý, Co-oxidation kinetic model for the thermal oxidation of polyethylene-un saturated substrate systems, Polym. Degrad Stab. 98 (2013) 1081-1088, doi:10.1016/j.polymdegradstab.2013.01.008.

[40] A.F. Reano, A. Guinault, E. Richaud, B. Fayolle, Polyethylene loss of ductility during oxidation: Effect of initial molar mass distribution, Polym. Degrad. Stab. 149 (2018) 78-84, doi:10.1016/j.polymdegradstab.2018.01.021.

[41] X. Colin, B. Fayolle, L. Audouin, J. Verdu, About a quasi-universal character of unstabilised polyethylene thermal oxidation kinetics, Polym. Degrad. Stab. 80 (2003) 67-74, doi:10.1016/S0141-3910(02)00384-1.

[42] J. Huang, W. Minne, R. Drozdzak, G. Recher, E. Richaud, P.Y. Le Gac, Thermal oxidation of poly(Dicyclopentadiene) Decomposition of hydroperoxides, Polym. Degrad. Stab. 174 (2020) 109102, doi:10.1016/j.polymdegradstab.2020.109102.

[43] Nadjet Khelidj, Ageing of cable insulators made of polyethylene in nuclear environment., Engineering Sciences [physics]. Arts et Métiers ParisTech (NNT: 2006ENAM0033) (2006) In this issue.

[44] E. Richaud, X. Colin, B. Fayolle, L. Audouin, J. Verdu, Induction period in the low-temperature thermal oxidation of saturated hydrocarbons: Example of polyethylene, Int. J. Chem. Kinet. 40 (2008) 769-777, doi:10.1002/kin.20347.

[45] J.L. Bolland, G. Gee, Kinetic studies in the chemistry of rubber and related materials. II. The kinetics of oxidation of unconjugated olefins, Trans. Faraday Soc. 42 (1946) 236-243.

[46] E. Denisov, I. Afanas, Oxidation and Antioxidants in Organic Chemistry and Biology ev, Boca Raton, 2005 First Edit.

[47] N.C. Billingham, M.N. Grigg, The kinetic order of decomposition of polymer hydroperoxides assessed by chemiluminescence, Polym. Degrad. Stabilty. 83 (2004) 441-451, doi:10.1016/j.polymdegradstab.2003.06.001. 
[48] L. Zlatkevich, On the kinetic order of decomposition of polymeric hydroperoxides, Polym. Degrad. Stab. 83 (2004) 369-371, doi:10.1016/j.polymdegradstab. 2003.09.006.

[49] J.L. Henry, A.L. Ruaya, A. Garton, The kinetics of polyolefin oxidation in aqueous media, J. Polym. Sci. Part A. 30 (1992) 1693-1703, doi:10.1002/pola.1992. 080300822 .
[50] J. Lacoste, D.J. Carlsson, D.M.W. S.Falicki, Polyethylene hydroperoxide decomposition products, Polym. Degrad. Stab. 34 (1991) 309-323, doi:10.1016/ 0141-3910(91)90125-B.

[51] A.M. Visco, N. Campo, L.I. Vagliasindi, G. Tabbì, Study of the radical species induced by electron-beam irradiation in vacuum on biomedical UHMWPE, Int. J. Polym. Anal. Charact. 15 (2010) 424-437, doi:10.1080/1023666X.2010.510109. 